\title{
Proportion of Osteoarthritis Knee among Older Adults Presenting with Knee Complaints as Assessed Using American College of Rheumatology (ACR) Criteria at A Tertiary Care Hospital, Kollam
}

Indu $D^{1}$, Asha K P $^{2}$, Manoj Kumar $S^{3}$, Anuja $U^{4}$

${ }^{1}$ Additional Professor, Community Medicine, Government Medical College Thiruvananthapuram, Kerala, India.

${ }^{2}$ Associate Professor, ${ }^{4}$ Professor, Community Medicine, ${ }^{3}$ Professor, Orthopedics, Government Medical College,

Kollam, Paripally, Kerala India.

Correspondence : Dr Indu D., Email: drindumanoj@gmail.com

\section{Abstract:}

Introduction: Osteoarthritis is one of the most prevalent musculoskeletal disorders seen as age increases. Among older individuals it leads to persistent complaints, disability and health care consultations. Objective: To estimate the proportion of osteoarthritis knee using American College Of Rheumatology (ACR) criteria among older individuals presenting with history of persistent knee complaints in a tertiary care setting. Method: A hospital based cross-sectional study was conducted to assess the proportion of osteoarthritis knee among older patients presenting with persistent knee complaints in orthopedic OP of Government Medical College Kollam. A semi-structured questionnaire was used to collect data regarding socio-demographic profile. Assessment of osteoarthritis knee was done Using American College Of Rheumatology (ACR) Criteria. Results: The proportion of osteoarthritis in any knee among older adults was found to be $72 \%$, with bilateral osteoarthritis knee seen in 38.5\%. Among those affected, 84\% were women. Knee pain, presence of crepitus and bony tenderness were the most common findings among those with OA knee. Conclusion: The proportion of OA knee was found to be higher among the study population. Older age group and females were more prone to osteoarthritis of knee. An estimate of the burden of OA in older patients will help policy makers in planning public health programs to improve their health condition and quality of life.

Key words: American College of Rheumatology (ACR) Criteria, Knee joint, Osteoarthritis

\section{Introduction:}

Osteoarthritis is a chronic progressive musculoskeletal disorder affecting the joints. Worldwide $7 \%$ of the global population is affected by osteoarthritis. ${ }^{[1]}$ The Global Burden of Disease Study 2019 lists osteoarthritis as the 15th highest cause of years lived with disability (YLDs) worldwide. ${ }^{[1]}$ Osteoarthritis was responsible for $2 \cdot 2 \%(1 \cdot 3-4 \cdot 1)$ of

\begin{tabular}{|c|l|}
\hline Quick Response Code & Access this article online \\
\hline & Website : \\
\cline { 2 - 2 } & www.healthlinejournal.org \\
\hline
\end{tabular}

total global YLDs, accounting for 18.9 million (95\% UI 9.57-37.7) global YLDs in 2019. Among these OA knee, hip, hand, and other site contributed $60.9 \%$, $5 \cdot 5 \%, 23 \cdot 5 \%$, and $10 \cdot 2 \%$ of OA YLDs, respectively. ${ }^{[2]}$ Among individuals aged 40 years and above, the global prevalence of OA knee was found to be $22.9 \%$ (95\% CI, 19.8\%-26.1\%). ${ }^{[3]}$ There are an estimated 654.1 (95\% CI, 565.6-745.6) million individuals aged 40 years and above with OA knee worldwide in

\section{How to cite this article : \\ Indu D, Asha K P, Manoj Kumar S, Anuja U. Proportion of Osteoarthritis Knee among Older Adults Presenting with Knee Complaints as Assessed Using American College of Rheumatology (ACR) Criteria at A Tertiary Care Hospital, Kollam. Healthline. 2021; 12(1): 10-14.}


$2020 .{ }^{[3]}$ The prevalence of OA knee among individuals aged 40 years and above in India was estimated to be $28.7 \%$. ${ }^{[4]}$ There was variation in the prevalence of OA knee among individual cities, with Agra (35.5\%), Bangalore (26.6\%), Kolkata (33.7\%), Dehradun $(27.2 \%)$, and Pune (21.7\%). ${ }^{[4]}$ In kerala the prevalence of knee osteoarthritis among women aged above 40years was $41.6 \%$ (95\% CI$41.6 \pm 1.25 \%$ ), with $66.2 \%$ having bilateral osteoarthritis of the knee joint. ${ }^{[5]}$ The prevalence of osteoarthritis increases with age ${ }^{[6]}$ and with many Asian countries ageing rapidly its fast becoming a major problem. People above 60 years constitute $13 \%$ of Kerala's population as compared to the national figure of $8.2 \%$ (Census 2011). Osteoarthritis of knee is most often associated with knee pain ${ }^{[7]}$ which affects the quality of life as well as the economic productivity of affected individuals. Even though the cause of osteoarthritis is not fully understood, prevention and early diagnosis is the most effective strategy to prevent further deterioration of this condition. With changes in lifestyle, the prevalence of OA knee has increased considerably over the years. Even though the number of people affected by osteoarthritis has increased, it continues to be neglected among non-communicable diseases. The health concerns of those affected has often been downplayed and is often seen as an inevitable consequence of ageing. Filling the prevailing knowledge gaps in the burden of osteoarthritis, will help to bring about a shift in policy and health care delivery. This is much needed to highlight the importance of public health interventions and health care approaches needed to decrease burden associated with osteoarthritis. This study aims to estimate the burden of osteoarthritis knee among older patients presenting with persistent knee complaints in a tertiary care setting.

\section{Method:}

A hospital based cross sectional study was conducted in the department of Orthopaedics, Government Medical College Kollam, which is a tertiary care centre in Kollam district of Kerala. The out-patient wing of department of Orthopedics caters to about 150 to 200 patients daily of which majority are female patients. Patients above 40 years attending the orthopedic outpatient of Government Medical College Kollam, with history of persistent knee complaints for the past 6 months were included in the study. Patients aged above 40 yrs were included as increase in age increases the risk of degenerative musculoskeletal changes. ${ }^{[18]}$ The Zoetermeer survey by Van Saase et $\mathrm{al}^{[19]}$ showed an increase in prevalence of OA knee with the onset of forties. Patients not giving consent and those with history of trauma, fracture or rheumatoid arthritis were excluded from the study. Based on a study by Chandra Prakash Pal et a ${ }^{[8]}$ the prevalence of OA knee was found to be $28.7 \%$.Applying in $n=\left(Z_{1-\alpha / 2}\right)^{2} P Q / d^{2}$ and considering an alpha error of $5 \%$, absolute precision $7 \%$ and non-response rate of $10 \%$, the sample size was fixed at 200 . All consecutive patients who met the eligibility criteria and gave consent were included in the study till the required sample size was met. Details regarding their demographic profile like age, gender, education, occupation and presenting complaints were collected using a semi-structured interviewer administered questionnaire. American College of Rheumatology (ACR) criteria was used to diagnose OA knee.

American College of Rheumatology (ACR) criteria for diagnosing osteoarthritis of knee joint is presence of pain in knee joint and any three of 6 factors listed below. ${ }^{[9]}$

\section{Age more than 50 years}

2. Presence of crepitus on active motion

3. Less than 30 min of morning stiffness

4. Bony tenderness

5. Bony overgrowth

6. No palpable warmth of synovium.

Data was analysed using Epi info(version 3.5.3), qualitative data was expressed in proportions and, quantitative data in mean \pm standard deviation. Associations were tested for significance using Chisquare test, and $\mathrm{P}$ value $<0.05$ was taken as significant. Study period was from 2018 to 2019 after 
obtaining permission from Institutional Human Ethics Committee of Government Medical College Paripally Kollam.

\section{Results:}

In this hospital based study, majority of the study participants were aged above 50 years. Mean age was 56.88 years with a SD of 9.06 years. Women constituted $84.5 \%$ of the study population. (Table 1 ) Most of the study population had education up to middle or high school (45\%), with $40 \%$ up to higher secondary school and $13.5 \%$ degree and above. Very few were illiterate or studied up to primary school. Majority of the study subjects (72\%) were home makers or unskilled workers and $16 \%$ were semiskilled and $9 \%$ professionals.

The proportion of osteoarthritis in any knee among patients aged above 40 years with persistent knee complaints as assessed using ACR Criteria was found to be $72 \%$ ( 95\% CI 65\% to 78\%). Among the study population, bilateral osteoarthritis knee was seen in $38.5 \%$ (95\% CI $31 \%$ to $45 \%$ ). (Table2) Among the study participants, $84 \%$ of those affected were women. Among women with OA knee, bilateral OA knee was seen in $87 \%$.Among those with OA knee, it was seen that as compared to unilateral OA knee, there was a significant increase of bilateral OA knee with age (Chi square value-10.02 and $p$ value $<0.01$ ). (Table 3) The most common symptom was pain, followed by crepitus and bony tenderness. (Table 4)

\section{Discussion:}

Osteoarthritis of the knee is a progressive, degenerative joint disease leading to functional impairment and disability. Even though multiple factors like genetics, obesity, trauma, metabolic imbalances etc are involved in the causation of osteoarthritis, it is seen that prevalence of OA knee increases with age. ${ }^{[11]}$ In this study proportion of osteoarthritis in any knee was found to be $72 \%$, with $38.5 \%$ having bilateral OA knee. The high proportion of OA might be due to the fact that, only patients aged above 40 years with persistent knee complaints were included in this study. Age is one of the most common risk factor for most non communicable diseases.
Table 1: Socio-demographic characteristics of study participants $(n=200)$

\begin{tabular}{|c|c|c|c|}
\hline \multicolumn{1}{|c|}{ Demographic variables } & Number & Percentage \\
\hline \multirow{4}{*}{$\begin{array}{c}\text { Age } \\
\text { (years) }\end{array}$} & $40-50$ & 53 & $26.5 \%$ \\
\cline { 2 - 4 } & $51-60$ & 70 & $35 \%$ \\
\cline { 2 - 4 } & $61-70$ & 63 & $31.5 \%$ \\
\hline \multirow{4}{*}{$\begin{array}{c}\text { Gender } \\
\text { Religion }\end{array}$} & Male & 31 & $15 \%$ \\
\cline { 2 - 4 } & Female & 169 & $84.5 \%$ \\
\cline { 2 - 4 } & Hindu & 150 & $75 \%$ \\
\cline { 2 - 4 } & Muslim & 38 & $19 \%$ \\
\hline \multirow{4}{*}{$\begin{array}{c}\text { Type } \\
\text { of } \\
\text { family }\end{array}$} & Joint & 15 & $7.5 \%$ \\
\cline { 2 - 4 } & Nuclear & 176 & $88 \%$ \\
\cline { 2 - 4 } & Extended & 9 & $4.5 \%$ \\
\hline
\end{tabular}

Table 2: Proportion of osteoarthritis knee among participants $(n=200)$

\begin{tabular}{|c|c|c|c|}
\hline Variable & \multicolumn{3}{|c|}{ Number (\%) } \\
\hline \multirow{2}{*}{$\begin{array}{c}\text { Bilateral } \\
\text { OA Knee }\end{array}$} & $\begin{array}{c}77 \\
(38.5 \%)\end{array}$ & Males & $10(13 \%)$ \\
\cline { 3 - 4 } & & Females & $67(87 \%)$ \\
\hline \multirow{2}{*}{$\begin{array}{c}\text { OA of } \\
\text { any knee }\end{array}$} & $\begin{array}{c}144 \\
(72 \%)\end{array}$ & Males & $23(16 \%)$ \\
\cline { 3 - 4 } & & Females & $121(84 \%)$ \\
\hline
\end{tabular}

Table 3: Age specific distribution of osteoarthritis knee

\begin{tabular}{|c|c|c|c|}
\hline $\begin{array}{c}\text { Age } \\
\text { (years) }\end{array}$ & $\begin{array}{c}\text { Unilateral } \\
\text { OA } \\
\text { knee (\%) } \\
(\mathrm{n}=67)\end{array}$ & $\begin{array}{c}\text { Bilateral } \\
\text { OA } \\
\text { knee (\%) } \\
(\mathrm{n}=77)\end{array}$ & Total \\
\hline $40-50$ & $14(21 \%)$ & $3(3.8 \%)$ & $17(12 \%)$ \\
\hline $51-60$ & $23(34 \%)$ & $34(44.1 \%)$ & $57(39 \%)$ \\
\hline$>60$ & $30(45 \%)$ & $40(51.9 \%)$ & $70(49 \%)$ \\
\hline Total & $67(100 \%)$ & $77(100 \%)$ & $144(100 \%)$ \\
\hline
\end{tabular}

(Chi square value-10.02 and $p$ value $<0.01$ ) 
Table 4: Distribution of signs and symptoms among study subjects with OA Knee*

\begin{tabular}{|c|c|c|c|c|}
\hline \multirow{2}{*}{ Symptoms } & \multicolumn{2}{|c|}{ OA right knee (n=112) } & \multicolumn{2}{c|}{ OA left knee (n= 110) } \\
\cline { 2 - 5 } & Number & $\%$ & Number & $\%$ \\
\hline Pain & 112 & $100 \%$ & 110 & $100 \%$ \\
\hline Morning stiffness & 26 & $23.2 \%$ & 24 & $21.8 \%$ \\
\hline Crepitus & 95 & $84.81 \%$ & 101 & $91.8 \%$ \\
\hline Bony tenderness & 75 & $67 \%$ & 72 & $65.4 \%$ \\
\hline Bony overgrowth & 13 & $11.6 \%$ & 19 & $17.3 \%$ \\
\hline No palpable warmth of synovium & 102 & $91.1 \%$ & 98 & $89.1 \%$ \\
\hline
\end{tabular}

*Multiple responses

With increasing age the risk of degenerative musculoskeletal changes also increases. Older age and history of persistent knee complaints increased the baseline risk of the study population to osteoarthritis. A study conducted in Uttar Pradesh by Sood et $\mathrm{al}^{[10]}$ showed a prevalence of $78.2 \%$ among patients complaining of knee pain. A study among elderly in urban slums of Delhi by Singh AK et al $^{[6]}$ showed a prevalence of osteoarthritis knee to be $41.1 \%$, with $37.7 \%$ having bilateral OA knee. A study by Sharma MK et $\mathrm{al}^{[11]}$ showed a prevalence of osteoarthritis among elderly to be $56.6 \%$, and also a higher prevalence of $47.3 \%$ among females aged above 40 years.

In this study among those with osteoarthritis knee $84 \%$ were women, and among those with bilateral osteoarthritis knee, $87 \%$ were women. In a study by Iqbal $\mathrm{MN}$ et $\mathrm{al}^{[12]}$ the prevalence of osteoarthritis was observed to be $74 \%$ among women. A study by Salve et $\mathrm{al}^{[13]}$ found the prevalence of osteoarthritis knee among perimenopausal women to be $47.3 \%$. Studies have shown that women are at increased risk of osteoarthritis as age advances due to lower estrogen at menopause and the role of estrogen in influencing chondrocyte function. ${ }^{[14,15]}$

This study observed an increase in occurrence of osteoarthritis knee with age, with 48.6\% among those affected being above 60 years. The Framingham Osteoarthritis Study by Felson et $\mathrm{al}^{[16]}$ observed an increase in osteoarthritis associated with age. In this study, among those with bilateral OA knee, 51.9\% were aged above 60yrs. Even though aging is strongly associated with development of osteoarthritis, the exact mechanism is still not fully understood. A meta-analysis by Blagojevic et $\mathrm{al}^{[17]}$, reported obesity, female gender, history of previous knee injury and age as risk factors of OA knee. The interaction of ageing in conjunction with other risk factors can determine the progression of osteoarthritis in an individual.

Among those with OA knee, the most common symptom was pain, followed by crepitus and bony tenderness. All patients diagnosed with OA knee reported pain at the knee joint. A similar finding was seen in the study by Singh AKet al. ${ }^{[6]}$ As osteoarthritis progresses, it leads to thinning and breakdown of cartilage. This results in sclerosis of the subchondral bone, formation of marginal osteophytes and inflammation of synovial membrane. This constant inflammation and stiffness results in pain and discomfort during movement. ACR criteria can be effectively used in early diagnosis OA knee among those with persistent knee complaints. 


\section{Conclusion:}

The proportion of OA knee was found to be higher among those with persistent knee complaints and it is seen to increase with age. It was found to be higher among females as compared to males. There is an increase in occurrence of bilateral OA knee with age. The most common symptom was pain, followed by crepitus and bony tenderness. Knee pain associated with osteoarthritis is a key symptom and is often associated with seeking health care.

\section{Recommendations:}

Comprehensive knee examination and assessment using ACR criteria can be used for early diagnosis and thus help in preventing deterioration, and reducing suffering and disability. To improve functional outcomes, it is important to screen those presenting with knee complaints for osteoarthritis. An assessment of burden of osteoarthritis is necessary for the health system for proper planning and policy making and to bring to focus neglected non communicable diseases like osteoarthritis.

\section{Declaration:}

Funding: Nil

\section{Conflict of Interest: Nil}

\section{References:}

1. Global Burden of Disease Collaborative Network. Global Burden of Disease Study 2019 (GBD 2019) results. 2020. http://ghdx.healthdata.org/gbdresults-tool

2. Global Burden of Disease Collaborative Network. Global Burden of Disease Study 2019 (GBD 2019) results. Osteoarthritis - level 3 cause. 2020

3. Cui A, Li H, Wang D, Zhong J, Chen Y, Lu H. Global, regional prevalence, incidence and risk factors of knee osteoarthritis in population-based studies. EClinicalMedicine. 2020 Nov 26;2930:100587. doi: 10.1016/j.eclinm.2020.100587.

4. Kumar H, Pal CP, Sharma YK, Kumar S, Uppal A. Epidemiology of knee osteoarthritis using Kellgren and Lawrence scale in Indian population. J Clin Orthop Trauma. 2020 Feb;11(Suppl 1):S125S129. doi: 10.1016/j.jcot.2019.05.019. Epub 2019 May 24. PMID: 31992932; PMCID: PMC6977151.

5. Bhaskar, A., Areekal, B., Vasudevan, B., R., A., Ravi, S., \& Sankar, S. (2016). Osteoarthritis of knee and factors associated with it in middle aged women in a rural area of central Kerala, India. International Journal of Community Medicine And Public Health, 3(10), 2926-2931. doi:http://dx.doi.org/10.18203/ 2394-6040.ijcmph20163385
6. Singh AK, Kalaivani M, Krishnan A, Aggarwal PK, Gupta SK. Prevalence of Osteoarthritis of Knee Among Elderly Persons in Urban Slums Using American College of Rheumatology (ACR) Criteria. J Clin Diagn Res. 2014;8(9):JC09-JC11. doi:10.7860/JCDR/2014/7763.4868

7. Hawker GA, Stewart L, French MR, Cibere J, Jordan JM, March L, et al. Understanding the pain experience in hip and knee osteoarthritis--an OARSI/OMERACT initiative. Osteoarthr Cartil. 2008;16:415-22.

8. Pal CP, Singh P, Chaturvedi S, Pruthi KK, Vij A. Epidemiology of knee osteoarthritis in India and related factors. Indian J Orthop. 2016 Sep; 50(5):518-522.

9. Johns Hopkins Arthritis Centre ACR clinical classification criteria for OA of Knee. http://www.Hopkins arthritis. org/physiciancorner /education/acr /acr.Html\#class_knee

10. Sood A, Sood A. Prevalence of knee osteoarthritis in elderly persons in a district of central Uttar Pradesh: a cross sectional study. Int J Health Sci Res. 2015; 5(9):89-93

11. Sharma M K, Swami H M, Bhatia V, Verma A, Bhatia S, Kaur G. An epidemiological study of correlates of osteo-arthritis in geriatric population of UT Chandigarh. Indian J Community Med 2007;32:77-8

12. Iqbal MN, Haidri FR, Motiani B, Mannan A. Frequency of factors associated with knee osteoarthritis. J Pak Med Assoc 2011; 61 (8): 786-9

13. Salve H, Gupta V, Palanivel C, Yadav K, Singh B. Prevalence of Knee Osteoarthritis amongst preimenopausal women in an Urban Resettlement Colony in south Delhi. Ind J of Pub Health vol 54 (3):155-7

14. Gokhale JA, Frenkel SR, Dicesare PE.Estrogen and osteoarthritis. Am J Orthop 2004;33:71-80

15. Borjesson AE, Lagerquist MK, Windahl SH, Ohlsson C. The role of estrogen receptor alpha in the regulation of bone and growth plate cartilage. Cellular and molecular life sciences: CMLS. 2013;70(21):4023-37.

16. Felson DT, Naimark A, Anderson J et al (1987) The prevalence of knee osteoarthritis in the elderly. The Framingham Osteoarthritis Study. Arthritis Rheum 30:914-918.

17. Blagojevic M, Jinks C, Jeffery A, et al. Risk factors for onset of osteoarthritis of the knee in older adults: a systematic review and meta-analysis. Osteoarthritis Cartilage. 2010;18:24-33.

18. Shane Anderson A, Loeser RF. Why is osteoarthritis an agerelated disease?. Best Pract Res Clin Rheumatol. 2010;24(1) : 15-26.

19. Van Saase JL, van Romunde LK, Cats A, Vandenbroucke JP, Valkenburg HA. Epidemiology of osteoarthritis: Zoetermeer survey. Comparison of radiological osteoarthritis in a Dutch population with that in 10 other populations. Ann Rheum Dis. 1989;48(4):271-280. 